\title{
MODA INCLUSIVA: PERCEPÇ̃̃O DE MULHERES OBESAS EM RELAÇÃO AO CORPO E AO VESTUÁRIO
}

\author{
INCLUSIVE FASHION: PERCEPTION OF OBESE WOMEN RELATING BODY AND CLOTHING
}

\section{RESUMO}

Este artigo aborda o tema da percepção do corpo entre mulheres obesas, discutindo o papel do vestuário no processo de exclusão/inclusão social. Trata-se de uma pesquisa qualitativa caracterizada por estudo observacional descritivo e pesquisa de campo, que se utilizou de procedimentos técnicos tais como entrevistas semiestruturadas aplicadas com mulheres maiores de 18 anos, com IMC - índice de massa corporal - de 25 a 29,9 e com IMC de 30 a 34,9. Os resultados indicam que as mulheres entrevistadas sentem insatisfação em relação aos seus corpos e, frequentemente, costumam comparar-se aos estereótipos de beleza difundidos pela mídia, o que lhes causa frustração e sentimentos de inferioridade. É possível inferir que se o vestuário não contempla as necessidades dos diferentes corpos existentes, a moda, no contexto extra passarelas, acaba por ser excludente.

Palavras-chave: Corpo. Mulheres. Obesidade. Moda. Inclusão Social.

\begin{abstract}
This article addresses the issue of body perception among obese women, discussing the role of clothing in the process of social exclusion/inclusion. This is a qualitative research characterized by descriptive observational study and field research, which was used technical procedures such as semi-structured interviews applied to women over 18 years with a BMI - body mass index - from 25 to 29,9 and BMI from 30 to 34,9 . The results indicate that the women interviewed felt dissatisfaction with their bodies and often tend to compare themselves to beauty stereotypes disseminated by media, which causes them frustration and feelings of inferiority. It is possible to infer that if the clothing does not address the needs of the different bodies, the fashion, in the extra catwalks context, turns out to be exclusionary.
\end{abstract}

Keywords: Body. Women. Obesity. Fashion. Social Inclusion.

\author{
Bruna Pacheco \\ Universidade FEEVALE. Email: brunapacheco@feevale.br \\ Jacinta S. Renner \\ Universidade FEEVALE. Email: jacinta@feevale.br \\ Margarete F. Nunes \\ Universidade FEEVALE. Email: marga.nunes@feevale.br \\ Ana L. C. Rocha \\ Universidade FEEVALE. Email: analuiza2@feevale.br
}




\section{Introdução}

Este artigo é fruto de uma pesquisa sobre moda, obesidade e processos de exclusão/inclusão social. As questões orientadoras da respectiva pesquisa ligam-se à percepção de mulheres obesas em relação ao vestuário e à aquisição de peças de tamanhos maiores no mercado. Quais as principais dificuldades dessas mulheres quando buscam compor o seu vestuário? Como o mercado da moda pode ir ao encontro das expectativas dessas mulheres e, ao mesmo tempo, oferecer um vestuário que contribua para o seu conforto e bem-estar? Sabe-se, de antemão, da dificuldade de algumas mulheres em encontrar peças fora do padrão corporal idealizado pela sociedade de consumo. Por causa disso, por meio do estudo e da pesquisa, este trabalho tem a intenção de contribuir com a reflexão sobre o tema e oferecer subsídios aos profissionais da moda que buscam atender a demanda deste público, que hoje já é quase metade da população brasileira.

Falar sobre o percurso metodológico desta pesquisa implica em demarcar o diálogo estabelecido entre os estudos relacionados à moda e os estudos sobre processos de exclusão/inclusão social na sociedade brasileira contemporânea. Nesse sentido, não foi difícil chegar ao tema da obesidade, haja vista os discursos e práticas sociais que impõem às mulheres uma determinada construção de corpo, na qual se vincula, também, a adesão a estilos de vestuário, modos de vestir-se e a incorporação de determinadas técnicas corporais (MAUSS, 2003). Assim como as mulheres, todos os sujeitos, de modo geral, deparam-se com uma ordem consentida em torno da gordura corporal, a partir da qual constroem um universo simbólico. Não é preciso "interditar" a gordura, ela já está posta como um valor negativo nas relações sociais (MATTOS, PERFEITO, CARVALHO e RETONDAR, 2012).

As interlocutoras da pesquisa são mulheres maiores de 18 anos, com IMC Índice de Massa Corpórea - de 25 a 29,9, que indicam sobrepeso, e com IMC de 30 a 34,9, que representam a obesidade leve. ${ }^{1} \mathrm{O}$ grupo consiste em 8 mulheres que, no período, foram entrevistadas individualmente em local pré-estabelecido de acordo com a comodidade e a facilidade exigidas por cada uma delas. Assim, seis entrevistas foram realizadas pessoalmente, uma através de conversa de vídeo pela internet e uma através de e-mail. Neste último caso, as perguntas foram enviadas por escrito. As participantes tiveram o seu anonimato garantido e resguardados os preceitos éticos da pesquisa, ao assinarem o Termo de Consentimento Livre e Esclarecido, por meio do qual se garantiu a confidencialidade das informações obtidas e a preservação das identidades de todas as participantes da pesquisa. As nossas interlocutoras são apresentadas por codinomes de flores: Rosa, Orquídea, Margarida, Tulipa, Azaleia, Violeta, Dália e Acácia. São mulheres de 22 a 35 anos, cuja altura varia entre 1 m e 6o

1 O padrão internacional existente atualmente para o cálculo do sobrepeso e obesidade é o Índice de Massa Corpórea (IMC). O peso da pessoa (em kg) é dividido pela sua altura ao quadrado. $\mathrm{IMC}=$ peso $(\mathrm{kg}) /$ altura $^{2}(\mathrm{~m})$. Classificação IMC: abaixo do peso, IMC abaixo de 18,5; peso normal, IMC de 18,5 a 24,9; sobrepeso, IMC de 25, o a 29,9; obesidade leve, IMC de 30, o a 34,9; obesidade moderada, IMC de 35, o a 39,9; obesidade mórbida, IMC 40 para mais (STURMER, 2001, p.19). 
$\mathrm{cm}$ a $1 \mathrm{~m}$ e $70 \mathrm{~cm}$, pesam de $75 \mathrm{~kg}$. a $105 \mathrm{~kg}$, o IMC varia de sobrepeso ( 3 interlocutoras) à obesidade I ( 5 interlocutoras). O grupo de interlocutoras faz parte da rede social das pesquisadoras e reside na região metropolitana da grande Porto Alegre. Após o aceite do convite para a participação na pesquisa, agendou-se horário e local de acordo com a disponibilidade de cada uma das interlocutoras.

Como procedimentos da pesquisa foram realizados contatos prévios com as mulheres convidadas e, posteriormente, encontros para a coleta de dados. Desenvolveu-se um roteiro com perguntas abertas relativas à percepção do corpo e do vestuário. A entrevista semiestruturada, em geral, seguia uma ordem prevista, no entanto, em alguns momentos houve interferências a fim de se acrescentar perguntas que viessem a esclarecer algum aspecto relevante. Utilizou-se recurso de gravação de áudio para registro e posterior transcrição das entrevistas. A análise dos dados orientou-se pela técnica de triangulação, proposta por Minayo (2004), como estratégia de diálogo entre áreas distintas do conhecimento, possibilitando o entrelaçamento entre a teoria e a prática e a integração de vários pontos de vista, por meio do confronto entre o aparato conceitual da pesquisa e as visões de mundo apresentadas pelos sujeitos da pesquisa.

$\mathrm{O}$ artigo estrutura-se do seguinte modo: em um primeiro momento traz reflexões sobre o corpo feminino e a obesidade; a seguir, dá visibilidade às percepções dessas mulheres sobre o corpo, o vestuário e a obesidade, por meio das suas narrativas, analisando-as à luz dos estudos sobre a moda e os processos de exclusão/ inclusão social.

\section{A construção do corpo feminino e as mulheres obesas}

Apertados em espartilhos, com cinturas marcadas, soltos e livres, em suas mais diversas configurações, os corpos sempre sofreram modificações ao longo dos tempos. Se antes as próteses eram externas, através do uso de corpetes e acessórios que moldavam o corpo à força, hoje existe tecnologia e conhecimento suficientes que permitem a utilização de próteses internas para a transformação do corpo. Pode-se dizer que mudam os meios, mas os corpos continuam sendo construídos, esculpidos, modificados e transformados. Ao olhar para o corpo como um produto da cultura material, reifica-se o corpo, o mesmo é transformado em um objeto e passível de ser projetado, construído, remodelado e esculpido (FORMIGA, 2003, p. 3).

Estudos das ciências sociais mostram o interesse de homens e mulheres pelo seu próprio corpo, bem como os diferentes usos que esses sujeitos fazem dos seus corpos em diversas sociedades, ao longo do tempo. $\mathrm{O}$ corpo, enquanto entidade biológica, é o primeiro instrumento do homem, mas ele é, também, objeto da domesticação exercida pela cultura, sendo por ela apropriado e manipulado; o corpo é uma "montagem fisio-psico-sociológica" (MAUSS, 2003). Para Foucault (2002), em qualquer sociedade, o corpo está preso no interior de poderes muito apertados, 
submetido a limitações, proibições e obrigações. O corpo está subjugado a poderes disciplinares que lhe impõem rigidez, controle e repressão. Nesse sentido, Vigarello (2012, p. 134) expõe sobre o processo simbólico em torno do corpo feminino, "o papel específico de uma beleza feminina 'decorativa', assim como o igualmente específico das sanções que ela pode provocar, enfim a orientação da aparência feminina se direciona no sentido do acolhimento, do 'interior' e da 'ornamentação' ".

Devido a fatores subjetivos que formam o ato de percepção, homens e mulheres percebem seu corpo de modo diferente, atribuem significados simbólicos distintos, ainda que ambos tenham as mesmas percepções sensoriais. Esta diferenciação, no entanto, tem uma base objetiva. As mulheres são muito mais cobradas socialmente sobre sua aparência física, enquanto a sociedade aceita e "naturaliza" corpos masculinos que se distanciem de quaisquer padrões de beleza masculino. No caso dos homens, não se trata da falta de cuidado ou negligência - que geralmente é imputada às mulheres - mas da falta de tempo em função da vida profissional; a beleza da imagem do homem está atribuída às conquistas sociais e econômicas e associada à virilidade, agressividade e expectativas sociais (NOVAES e VILHENA, 2003). Historicamente, houve uma oposição entre os papéis masculinos e femininos; de um lado, o homem foi vinculado a representações de sexo forte, dominação, esfera pública e poder; de outro lado, a mulher foi associada ao sexo frágil, à subordinação, à esfera doméstica/ privada e ao "poder de manipulação" (BRUHNS, 1995). Os significados aí implícitos codificaram a definição social da mulher ao longo da história.

Segundo Novaes e Vilhena (2003, p. 11) "a imagem da mulher e do feminino continua associada à beleza, havendo cada vez menos tolerância para os desvios nos padrões estéticos socialmente estabelecidos". Em diferentes momentos e diferentes sociedades houve modelos normativos de beleza, o que difere na atualidade é o tipo de controle exercido sobre as formas do corpo. Um dos modos de controle é a imposição pelos discursos midiáticos de que ela pode ser bela se assim quiser, delegando a ela a grande responsabilidade de gerir esse corpo; se não é bela, é por conta de um fracasso ou incapacidade individual. Se antigamente as mulheres já se preocupavam com a beleza, hoje a sociedade impõe que elas sejam as responsáveis pela tarefa de "manterse bela”; ser bela é um dever social e até moral (VILHENA, NOVAES e ROCHA, 2008).

A corporeidade feminina é ilustrada por um corpo idealizado nos discursos da mídia, o qual se utiliza de elementos relacionados à juventude, ao vigor, potencializando a força e a beleza mediante à adoção de um conjunto de técnicas corporais (MAUSS, 2003) e estratégias que vão desde exercícios físicos, dietas, cirurgias a estilos de vestuário (FONTES, 2009). Todo este arsenal de estratégias promete potencializar a atração sexual do corpo feminino, dando-lhe um status adquirido através da jovialidade e da beleza e, consequentemente, criando a ilusão de felicidade e sucesso. A moda é uma das engrenagens que contribuem para colocar o corpo em evidência, e por trás deste consumo há "toda uma economia mobilizada para produzi-lo e mantêlo: cosméticos, medicação, cirurgias corretivas, alimentação, condicionamento físico, spas, regimes, indústria da moda etc." (MESQUITA e CASTILHO, 2011, p. 22). A mídia encontrou no "corpo perfeito" o discurso ideal para a difusão de todo um mercado para 
alcançá-lo e mantê-lo. Nesse sentido, a maioria das mulheres que não se enquadra no perfil de beleza preconizado questiona arduamente a validade dos desfiles, editoriais de moda e campanhas publicitárias, pois esses favorecem um único modelo de corpo (MATOS, SILVA, SILVA \& CUNHA, 20o8). Esse público tem dificuldade de encontrar roupas que deveriam ser criadas para favorecer as especificidades do seu corpo que difere do tão difundido corpo esguio.

Desfavorecidas por este padrão de moda, as mulheres obesas acabam seguindo as fórmulas estereotipadas difundidas pelas campanhas publicitárias por medo de desvencilhar-se do padrão, afinal é mais conveniente seguir o que está rigorosamente automatizado do que aventurar-se em algo desconhecido sem garantias (PRECIOSA, 2007). Como consequência, o apelo à beleza e o culto à boa forma tornou-se praticamente um estilo de vida a ser seguido e um martírio para a maioria das mulheres. Conforme Calanca (2008, p.17), "O ato de vestir 'transforma' o corpo, e essa transformação não se refere à um único significado, biológico ou fisiológico, mas a múltiplos significados" - religioso, estético, político, sociológico, psicológico. A roupa é um fator importante na relação do indivíduo com a sociedade.

Ao olhar de forma mais atenta a diversidade dos usuários, percebe-se que a indústria do vestuário atual se preocupa em satisfazer, em sua maioria, as expectativas de consumidores jovens, ávidos por novidades e por corpos esbeltos. Expectativas essas que são tanto individuais quanto sociais. Waizbort (2008, p. o9), parafraseando Simmel, lembra-nos do dualismo presente no universo da moda. Por um lado, moda é imitação, isto é, responde aos anseios humanos de interação e inserção em um grupo, oferecendo uma modalidade de identidade coletiva; por outro lado, moda é diferenciação, "portanto, tanto liga como separa, aproxima como afasta, torna distinto o indistinto".

Heinrich (2009, p. 2) afirma que "é importante ressaltar que a grande maioria dos produtos de vestuário que são disponibilizados no mercado se enquadra a determinados padrões corporais, daí a sensação de desconforto que os demais consumidores enfrentam". Aqueles que possuem medidas diferenciadas e se afastam dos padrões estéticos vigentes, por exemplo, os obesos, são excluídos da moda, encontrando dificuldades no momento de adquirir uma peça de roupa. As mulheres obesas tendem a sofrer discriminação, tanto pelas discursividades vigentes que têm como padrão de beleza a magreza quanto no momento da busca por vestuário, pois a maioria das lojas não oferece tamanhos maiores do que o 44 ou G, privando-as de se vestirem da forma como desejam, adequando-as ao que há disponível no mercado.

\section{Percepções do corpo e do vestuário entre mulheres obesas}

Jorge (2011) separa o ato perceptivo em dois componentes fundamentais: o primeiro, denominado objetivo, por meio do qual há a captação sensorial, estimulando as sensações; e o segundo, subjetivo, por meio do qual há a integração significativa, 
permitindo o conhecimento acerca do objeto captado. Perceber o mundo não depende só das qualidades objetivas de um fenômeno captado pelo aparelho sensorial (visão, tato, audição, olfato e paladar), pois a memória, a emoção e o raciocínio também atuam como filtros, introduzindo outros elementos. Portanto, o ato perceptivo apresenta uma tensão entre os aspectos sensoriais e aqueles da ordem das emoções, das representações sociais e dos significados.

Uma das primeiras perguntas que realizamos às nossas interlocutoras da pesquisa foi em relação ao momento da compra, se elas costumavam encontrar aquilo que procuravam em termos de vestuário, especialmente se encontravam roupas adequadas aos seus corpos. As respostas foram unânimes e muito semelhantes, relatando grande insatisfação em relação à roupa disponível no mercado para pessoas obesas. Paradoxalmente, no contexto dessa pesquisa, percebeu-se que o momento da compra tende a ser algo doloroso, oposto ao que a sociedade atual prega, de que o ato de consumir costuma ser um momento prazeroso. Barbosa (2004) expõe que o ato de comprar caracteriza-se pela busca de gratificação, muitas vezes sobrepondo-se à satisfação das necessidades. As narrativas das nossas interlocutoras apontaram para o inverso, para o sentimento de desconforto e frustração na experiência do consumo.

A interlocutora Orquídea relatou que sentia grande frustração quando ia em busca de vestuário, pois projetava uma imagem das roupas que gostaria de adquirir, mas, no momento de vestir, elas não assentavam em seu corpo: “[...] era difícil de tu achar alguma coisa que desse certo. Aí tu olhavas e tinha aquela imagem, tipo assim, vai dar... E quando eu colocava não fechava, não dava, saía frustrada”. Tulipa, quando questionada sobre a moda, respondeu que tinha interesse e a acompanhava, mas relatou: "Queremos usar a mesma coisa que o tamanho 38 e 36 usam, com a mesma modelagem, tudo igual, mas só que daí não fazem”. Já, a interlocutora Acácia comentou que normalmente as blusas ficam apertadas no seu corpo, constrangendo-a na hora de provar: "ternos, casacos, eles sempre ficam mais curtos por questão do tamanho do seio e às vezes nem fecham. As jaquetas jeans, nenhuma fecha”.

Seis mulheres responderam que roupas para a parte superior do corpo são mais fáceis de serem encontradas, sendo que metade das entrevistadas citou uma grande rede de lojas como principal local de compra; a calça foi apontada como a peça do vestuário mais difícil de ser encontrada com um bom caimento em relação aos seus corpos, sendo que todas as entrevistadas foram unânimes nessa questão. Violeta conta ainda que: "muitas vezes, com calças tenho experiências traumáticas, pois muitas peças não servem, chegando a provar até dez, doze calças e nenhuma servir". Ainda neste contexto, Margarida expôs que a sua experiência na compra de roupas também é frustrante: "[...] ou fica grande na cintura, ou fica grande não sei onde, não se adaptam, não é uma roupa que se encaixa certinho como em uma pessoa magra”.

O vestuário deveria ser acessível a todas as pessoas, permitindo a expressão da identidade e a liberdade para a adoção do estilo desejado (CRANE, 2006), mas percebe-se que para as mulheres com sobrepeso e obesidade isto nem sempre acaba se concretizando. A interlocutora Dália reforçou esta questão ao dizer: "às vezes 
eu compro porque serviu, mas não que fosse aquilo que eu procurava”. Orquídea acrescentou: “[...] até encontro roupas, mas são todas iguais”. Esses relatos, permeados por expressões corporais de constrangimento durante a entrevista, reportam às pesquisadoras o entendimento de que as interlocutoras anseiam em fazer parte do universo de consumo da moda. Este anseio denota o desejo de se identificar e pertencer a um grupo de mulheres consideradas socialmente belas, assim como integrar-se ao universo feminino sem o constrangimento de não se sentirem bem em função da vestimenta não adaptada aos seus gostos e necessidades. As autoras Novaes e Vilhena (2003) corroboram com este entendimento quando expõem que as pessoas obesas se privam de comprar o que querem, tendo que se contentar com as roupas que elas conseguem vestir em seus corpos.

Ao contextualizar a falta de vestuário para mulheres acima do peso, é relevante acrescentar dados de uma pesquisa realizada por Medeiros e Cardoso (2010), por meio da qual foram analisadas 40 lojas de varejo de moda feminina do Barra Shopping Sul, situado na zona sul da cidade de Porto Alegre. As pesquisadoras verificaram que 6o\% das lojas trabalham com numeração até o tamanho 46; 27,5\% comercializam até o tamanho $48 ; 7,5 \%$ trabalham com o manequim 50 ; e apenas $5 \%$ possuem numeração até o tamanho 52. Este resultado confirma o número escasso de opções disponíveis no mercado de vestuário para mulheres acima do peso, reforçando as respostas das interlocutoras, em que todas informaram ter dificuldade em encontrar roupas para suas numerações.

A partir das observações é possível inferir que, além da dificuldade de encontrar a numeração adequada, ainda existe a questão da roupa não apresentar um bom caimento, pois a moda é projetada para algumas numerações, como o tamanho 38. O bem vestir tem implícitas demandas técnicas que ultrapassam a questão da numeração em si, envolve um estudo do corpo e suas particularidades, algo que é abordado em poucas empresas de confecção existentes no mercado, pois o corpo obeso possui formas diferenciadas em comparação ao esbelto e esguio. Encontrar a numeração adequada é difícil, mas encontrar uma roupa no tamanho e que assente bem ao corpo com sobrepeso e obesidade, é de maior complexidade ainda.

A cultura do consumo defende a liberdade de escolha individual, a insaciabilidade, o consumo como uma forma de comunicação social, tendo o vestuário como um signo que carrega uma narrativa sobre o indivíduo que o ostenta. Conforme os relatos das entrevistadas, raramente isso se concretiza devido a indisponibilidade de roupas adequadas aos seus corpos. Nesse contexto, Valença (2009) expõe que "somos o que a roupa nos permite ser". No caso das interlocutoras, pôde-se perceber que esta relação raramente acontece. Isso decorre em função da oferta que é escassa, permitindo-lhes poucas escolhas, ou seja, acabam em contentar-se com o que encontram disponível no mercado e que sirva em seus corpos, sendo que muitas vezes este "servir" não implica necessariamente em um bom caimento. Por essas e outras questões, no que tange à adaptação ao vestuário, cinco entrevistadas comentaram que acabam por optar em mandar fazer as suas roupas em costureiras, tornando assim possível melhor escolha e vestibilidade ao seu corpo. 
Outro fator relevante é que além da falta de roupas adequadas, três interlocutoras relataram sofrer discriminação em lojas: “[...] eu evito entrar em lojas, exatamente por saber que não vou encontrar, que não vão me atender bem, eles te olham e nem te atendem às vezes" (Azaleia). Devido às experiências negativas, no momento da procura e da compra do vestuário, algumas afirmaram que já deixaram de frequentar eventos e de sair de casa por não possuírem a vestimenta adequada. Ainda, considerando a relação do vestir e o aspecto de participação social, a interlocutora Tulipa, ao fazer o relato de suas experiências, expressou grande insatisfação e frustração ao dizer que já deixou de ir em lugares devido ao fato de não encontrar vestuário adequado. Neste caso, apesar de ter vontade e condições de pagar pela roupa que deseja, não encontra tamanhos apropriados. A interlocutora acrescentou que já passou por experiências às quais "a própria vendedora diz: 'olha, não tem modelagem pra ti [...] muito triste, tu queres, tu podes ter, mas a loja, a marca em si, não tem”. Percebe-se então que o estigma da obesidade pode ser manifestado dentro da própria loja, podendo ser um dos fatores que influencia na preferência de algumas interlocutoras em confeccionar as suas roupas em costureiras ou procurar por lojas especializadas.

Outro aspecto de extrema relevância na abordagem sobre obesidade é o estigma que tende a acompanhar o cotidiano e a vida social dessas pessoas. Isso se torna evidente ao analisar as falas das interlocutoras, pois em todos os relatos sempre é citada a comparação em relação a mulheres com corpos ditados como normais ou com um ideal de beleza difundido pela mídia. As pessoas que vivem sob um estigma tendem a conviver com pessoas que partilham da mesma situação, pois isso proporciona alívio e conforto:

[...] hoje em dia eu tenho uma preocupação que eu me olho no espelho e me enxergo mais gorda do que eu sou, eu não me sinto satisfeita com o que eu vejo. Interfere no convívio? Interfere, com certeza, porque hoje eu me sinto mais confortável com as minhas amigas que tem sobrepeso, que pesam $100 \mathrm{~kg}$. E eu quando estou com elas me sinto muito mais tranquila para sentar, conversar de assuntos que a gente divide, do mesmo meio, do que quando estou com pessoas magras. (Rosa)

Mais de metade das entrevistadas relatou insatisfação com seu corpo e aparência. Quando elas se comparam com pessoas magras demonstram se sentir desconfortáveis, inferiores ou diferentes. Portanto, pôde-se perceber que o autojulgamento sobre o próprio corpo pode construir uma grande barreira na socialização, pois ao não se sentirem de acordo com o esperado, por não possuírem o corpo desejado, podem acabar se auto excluindo. Em diversas falas pôde-se constatar que as interlocutoras acreditam que frequentemente estão sendo julgadas pelas pessoas ao seu redor em função de seus corpos. Neste sentido, Spada (2009, pp. 6o61) explica que esta sensação que a pessoa obesa sente não é somente desgastante 
como imensamente sofrida: "[...] o nível de perseguição em que fica o indivíduo com obesidade é alto, pois sente que tem sempre alguém olhando, reparando e criticando o seu tamanho, culpando-o e rechaçando-o por sua gordura”.

A realidade vivenciada pelas mulheres obesas remete à condição de exclusão social pelo vestir, ou seja, o fato de não encontrarem a vestimenta adequada e que caia bem aos seus corpos as constrange e as limita em termos de convívio social. A interlocutora Azaleia, que é a entrevistada que possui o índice de IMC mais alto, comentou que já deixou de sair e frequentar rodas de amigos devido ao vestuário, mas que hoje já aceita melhor o seu corpo. Embora se perceba na fala da entrevistada que a barreira social diminuiu, ela afirma enfrentar o estigma da obesidade principalmente em festas e sente-se deslocada devido a vestir-se de forma diferente:

Eu não deixo de ir nos lugares, mas me sinto bem mal. [...] as pessoas te olham torto, parece que tu 'ui, o que esta pessoa está fazendo aqui? Ela não pode sair! Ela não pode se amar!'. Até quando eu vou sair com minhas amigas eu me sinto destoada, pois eu não uso roupa curta, e elas só usam isso. Estou destoando. (Azaleia)

No mesmo sentido, ao discutir o processo de exclusão/inclusão social pelo vestir, três interlocutoras citaram o sofrimento pela discriminação que as tem acompanhado desde a adolescência e que isto implica em problemas de pertencimento, o que tende a induzi-las à reclusão e à tristeza. Um exemplo disso é a fala da interlocutora Rosa: "parecia que eu não combinava com a minha família". A interlocutora acrescentou que se vestia com roupas largas tentando esconder o corpo para ficar mais parecida com o restante da família. Já, a interlocutora Acácia citou: "até o próprio uniforme da escola não era nem adequado, ficava apertado ou ficava grande demais e isso também causava mal-estar".

A moda deve ser acessível a todos os níveis e segmentos sociais, tanto no sentido de criar estilos que expressem múltiplas identidades quanto possibilitar a adoção e a ressignificação de estilos pelos mais diversos sujeitos. Corroborando com esta ideia, Grave (2010) aponta que a preocupação deveria ser de não segregar de forma alguma os diversos tipos de corpos existentes, mas de acolhê-los dentro de uma perspectiva de atendimento à sua qualidade de vida.

Em termos de concepção de produtos de moda, é necessário considerar a diversidade no momento da criação e do desenvolvimento de peças de vestuário. O corpo obeso possui particularidades que precisam ser observadas e, além disso, também é necessário acrescer as roupas com informações de moda atuais, senão o vestuário torna-se apenas um meio de sobrevivência, o qual a pessoa o utiliza como proteção, não para se comunicar e se expressar. A interlocutora Violeta, que trabalha no ramo do vestuário, comentou que "para que as peças favoreçam e colaborem esteticamente com a silhueta, é importante que se pense especificamente nos detalhes de volumes e ajustes, ressaltando a região mais bonita que deve ser 
valorizada, detalhe que é diferente para cada tipo de corpo". Ainda, na concepção da entrevistada, na elaboração de vestuário é necessário que as empresas de confecção observem as particularidades do corpo feminino com sobrepeso e obesidade. Este corpo é constituído de diferenças relevantes quando comparado com o corpo modelo, normatizado como referência de beleza atual. Para atender esta diversidade de forma satisfatória, o vestuário precisa considerar também o corpo acima do peso, e não tão somente o corpo idealizado, correspondente aos tamanhos 36 ou 38. Neste caso, vale trazer à discussão o princípio máximo da ergonomia que é a adaptação do produto, sistema e processo ao ser humano, e não o contrário, que é o que acontece na moda, os corpos se adaptando ao vestuário.

Cada corpo é singular. Até mesmo o vestuário elaborado para uma mulher que vista o tamanho 38 não abrange de forma satisfatória todas as usuárias desta numeração. Isto se deve em função das peculiaridades de cada corpo, pois algumas têm mais quadril, outras mais busto e assim por diante. Portanto, em se tratando de numerações maiores, este fato se agrava. O Brasil ainda é incipiente quando se trata de estudos acerca das medidas do corpo feminino, portanto não existe padronização de tamanhos. Confeccionar roupas adequadas a fim de atender pessoas acima do peso não é algo simples para uma empresa de confecção, mas com o crescente número de mulheres com sobrepeso e obesidade no Brasil, é necessário voltar os olhos para este público ávido por participar da moda e lhes permitir a inclusão a partir do ato de vestir o corpo e, assim, proporcionar o sentimento de identidade e pertencimento.

Percebeu-se ao longo das entrevistas que, a partir de experiências perceptivas, são formadas referências subjetivas que constroem a imagem corporal de cada indivíduo. Esta autoimagem, munida com a constante comparação e sentimentos de inferioridade, por não se sentir de acordo com os padrões corporais, pode induzir a estados de tristeza, baixa autoestima e até de reclusão social. Além da própria percepção e julgamento, as pessoas acima do peso ainda enfrentam o olhar da sociedade. Isso se configurou ao longo da pesquisa de campo, sendo que os relatos das interlocutoras foram permeados por experiências de preconceito, discriminação e intolerância à obesidade. Isso foi constatado não somente pelas verbalizações das entrevistadas, mas também pelas expressões corporais durante as entrevistas, pois em muitos momentos foram percebidos gestos e olhares que expressavam a vontade de esconder o corpo e o sentimento de vergonha dele.

A insatisfação com o próprio corpo e a discriminação presente na sociedade prejudicam o convívio social e geram sentimentos de infelicidade. "A exclusão social do obeso pressupõe também uma ausência de poder que traz embutida uma impossibilidade de exercitar sua cidadania. O obeso está tão acostumado a abrir mão dos prazeres que acaba abrindo mão também de seus direitos" (FREIRE, 2005, p. 1).

Sabe-se que a esfera visual é a primeira a se apresentar durante a socialização e que a vestimenta se enquadra neste domínio. Portanto, além da função de proteger o corpo, a roupa também tem implícita a competência de expressar opiniões, gostos, crenças e assim por diante, de quem a veste, dando a possibilidade ao indivíduo de misturar-se a um grupo ao vestir-se de forma homogênea ou de diferenciar-se 
perante os demais. Em termos de oferta e procura de vestimenta para obesos, além do número reduzido de oferta, ainda há o agravante de poucas roupas conterem informação de moda, bom caimento e conforto. Portanto, as mulheres que possuem o corpo acima do peso, além da frustração ao sentirem-se traídas pelo próprio corpo, da discriminação e atributos pejorativos que a sociedade lhes atribui, ainda enfrentam a realidade de não se sentirem incluídas no mercado da moda.

Segundo Martins (2008), a exclusão social é característica das sociedades contemporâneas, às quais vêm rapidamente transformando os seres humanos em descartáveis, reduzindo-os à condição de "coisa". Porém, o autor defende que não há exclusões consumadas, definitivas e irreversíveis. Por isso é que se pode pensar em processo de exclusão/inclusão. Para Sassaki, (2003), a inclusão social é um processo bilateral, no qual a sociedade e as pessoas excluídas buscam por soluções para equiparação de oportunidades para todos. Os principais princípios da inclusão citados pelo autor são: celebração das diferenças, direito de pertencer, valorização da diversidade humana, igual importância das minorias e cidadania com qualidade de vida.

Não conseguir estar incluída esteticamente, considerando que os padrões ideais sempre estão em alteração, define a busca interminável por um corpo perfeito. Constata-se isso ao observar-se as estatísticas, cada vez maiores, da quantidade de cirurgias estéticas realizadas anualmente; uma busca interminável por um corpo que nunca estará perfeito, pois sempre se buscará maneiras de deixá-lo ainda "melhor", este é o descontentamento que move grande parte das mulheres brasileiras.

\section{Considerações finais}

Ao investigar os processos de exclusão pelo vestir, pode-se afirmar que corpo e vestuário andam lado a lado, ao longo da história, e em tempos e espaços diversos há estereótipos normativos de beleza, vestimenta e conduta. Nas sociedades ocidentais contemporâneas, cultua-se o corpo magro e jovem. As mulheres que não estão de acordo com este padrão de beleza, imposto pela cultura do consumo, assimilam certo "fracasso pessoal", por vezes, incorporando visões depreciativas acerca do seu próprio corpo. Nesse caso, a não correspondência ao padrão exigido tende a ser visto como sendo única e exclusivamente sua culpa e desleixo. Portanto, as mulheres com sobrepeso e obesidade tendem a ser marginalizadas em meio a este cenário.

Por fim, é possível inferir que há uma insatisfação por parte da maioria das mulheres obesas em relação ao vestuário que há disponível no mercado, já que as empresas de confecção focam em atender públicos com corpos mais próximos do considerado ideal pela mídia. Neste sentido, a roupa tende a afetar o convívio social, a autoestima, a aceitação do eu e o sentir-se aceito e integrado na sociedade. $O$ culto ao corpo perfeito, esguio e em sintonia com o que é oferecido pela moda é uma condição imposta de forma mais contundente às mulheres. 
O problema norteador da pesquisa - qual a percepção das mulheres com obesidade e sobrepeso em relação ao vestuário e a implicação deste na exclusão/ inclusão social? - foi respondido ao constatar-se que as interlocutoras se sentem excluídas pelo universo da moda em função de destoarem do padrão físico cultuado pela mídia e terem dificuldade em encontrar vestuário adequado aos seus corpos. Verifica-se que esta não correspondência aos padrões corporais estéticos causa grande frustração e agrava-se pela falta de vestimenta.

\section{Referências}

BARBOSA, L. (2004). Sociedade de consumo. Rio de Janeiro: Jorge Zahar Ed.

BRUHNS, H. T. (1995). “Corpos femininos na relação com a cultura”. In: ROMERO, E. (comp.). Corpo, mulher e sociedade. Campinas, SP: Papirus. p. 71-97.

CALANCA, D. (2008). História social da moda. São Paulo: Senac.

CRANE, D. (2006). A moda e seu papel social: classe, gênero e identidade das roupas. São Paulo: Senac.

FONTES, M. (2009). "Os percursos do corpo na cultura contemporânea”. In: COUTO, E. S., \& GOELLNER, S. V. (comp.). Corpos mutantes: ensaios sobre novas (d)eficiências corporais. 2a ed., Porto Alegre: UFRGS. p. 75-88.

FORMIGA, S. (2003). "O design do corpo como determinante da identidade feminina". In: II SEMINÁRIO INTERNACIONAL EDUCAÇÃO INTERCULTURAL, GÊNERO E MOVIMENTOS SOCIAIS. Florianópolis: Identidade, diferença, mediações.

FOUCAULT, M. (2002). Vigiar e Punir: história da violência nas prisões. $25^{\underline{a}}$ ed. Petrópolis: Vozes.

FREIRE, D. S. (2005). A exclusão social do obeso. Disponível em <http://www. acimadopeso.com/xclusaobeso.pdf. >Acesso em 20 ago. 2016.

GRAVE, M. F. (2010). Modelagem tridimensional ergonômica. São Paulo, SP: Escrituras.

HEINRICH, D. P. (2009). "A Ergonomia e os princípios do conforto no design de produtos para vestuário: acerca dos dados antropométricos aplicados a públicos específicos". In: IV WORKSHOP DE ANÁLISE ERGONÔMICA DO TRABALHO UFV, I ENCONTRO MINEIRO DE ESTUDOS EM ERGONOMIA, Anais do I Encontro Mineiro de Estudos em Ergonomia. Viçosa, MG. 
JORGE, A. M. G. (2011). Introdução à percepção: entre os sentidos e o conhecimento. São Paulo: Paulus.

MATTOS, R. S., PERFEITO, R., CARVALHO, M. C., \& RETONDAR, J. (2012) “Obesidade e bullying na infância e adolescência: o estigma da gordura”. Demetra, 7 (2), p. 71-84.

MATOS, A. L. B., SILVA, C. M. S., SILVA, M. L., \& CUNHA, J. (2008). "Vestuário especial para desabilidade física”. In: 8 CONGRESSO BRASILEIRO DE PESQUISA E DESENVOLVIMENTO EM DESIGN. Anais. São Paulo, SP.

MARTINS, J. S. (2008). A sociedade vista do abismo: novos estudos sobre exclusão, pobreza e classes sociais. $3^{\underline{a}}$ ed. Petrópolis: Editora Vozes.

MAUSS, M. (2003). "As técnicas do corpo”. In: Sociologia e Antropologia. São Paulo: Cosac \& Naify.

MEDEIROS, F., CARDOSO, C. E. (2010). "Moda plus size para mulheres entre 25 a 55 anos no Brasil”. In: 6o COLÓQUIO DE MODA. Anais. São Paulo, SP. Disponível em: <http://www.coloquiomoda.com.br/anais/Coloquio\%2ode\%2oModa\%20-\%20 2010/71478_Moda_Plus_Size_para_Mulheres_entre_25_a_55_Anos_no_Bra.pdf>

MESQUITA, C., \& CASTILHO, K. (2011). Corpo, moda e ética: pistas para uma reflexão de valores. $2^{\underline{a}}$ ed. São Paulo: Estação das Letras e Cores.

MINAYO, M. C. S. (2004). Pesquisa social: teoria método e criatividade (23‥ ed.). Petrópolis, RJ: Vozes.

NOVAES, J. V.; VILHENA, J. (2003). "De Cinderela a moura torta: sobre a relação mulher, beleza e feiúra”. Interações, VIII (o15), 9-36.

PRECIOSA, R. (2007). Produção estética: notas sobre roupas, sujeitos e modos de vida. São Paulo, SP: Anhembi Morumbi.

SASSAKI, R. K. (2003). Inclusão: Construindo uma sociedade para todos. $5^{\text {a }}$ ed. Rio de Janeiro: WVA.

SPADA, P. V. (2009). Obesidade e sofrimento psíquico: realidade, conscientização e prevenção. São Paulo: Editora Unifesp.

STURMER, J. S. (2001). Reeducação alimentar: qualidade de vida, emagrecimento e manutenção da saúde. Petrópolis, RJ: Vozes. 
VALENÇA, L. A. (2009). "Gordo sim! Fora de moda, jamais!". In: III ENCONTRO DE ENSINO, PESQUISA E EXTENSÃO DA FACULDADE SENAC - PE. Disponível em: $<$ http://www.faculdadesenacpe.edu.br/encontro-de-ensino-pesquisa/2011/III/anais/ comunicacao/021_2009_ap_oral.pdf>. Acesso em 21 nov. 2015.

VIGARELLO, G. (2012). As metamorfoses do gordo: história da obesidade no Ocidente da Idade Média ao século XX. Trad. Marcus Penchel. Petrópolis, RJ: Vozes.

VILHENA, J., NOVAES, J. V.; ROCHA, L. (2008). "Comendo, comendo e não se satisfazendo: apenas uma questão cirúrgica?". Revista Mal-estar e Subjetividade, III (2), 379-406.

WAIZBORT, L. (2008). "Georg Simmel sobre a moda: uma aula." Iara Revista de moda, cultura e arte, $1(1)$. 